\title{
O que pode uma Língua: lições de gesto para o design agora
}

Julie de Araujo Pires;

Moisés Colares Barreto

resumo:

O trabalho traz reflexões surgidas no contato com a Língua Brasileira de Sinais e a cultura Surda, por meio de atividades de ensino, pesquisa e extensão universitária. A abordagem de investigações do design nas questões pertinentes às línguas de sinais se configura aqui como via de mão dupla, capaz de resultados, tanto pelas possibilidades que o design pode apresentar para garantir voz e inclusão social a todos os seres humanos, quanto pelos questionamentos emergentes no contato com uma língua que utiliza canal comunicativo visual-gestual. Como exemplos dessas aproximações, apresentamos projetos desenvolvidos pelos autores deste artigo, considerando fronteiras criativas entre design-arte e o foco em design para o ensino da Libras. As situações de projeto aqui narradas têm caráter experimental e postura investigativa aberta a contribuições possíveis, no sentido de ampliar horizontes acerca do entendimento da imagem, da linguagem, das línguas de sinais e da nossa própria língua, o português falado no Brasil.

palavras-chave:

design visual; língua; surdez; Libras 


\section{Primeiras palavras}

O presente trabalho também poderia ser nomeado, com a intenção do mais didático: "O que nós designers aprendemos ao aprender Libras". Pois, diante do aprendizado da Libras, experiência que impulsiona tantas reflexões e perspectivas, o que muda em nosso fazer e nos pensamentos envolvidos nos projetos de pesquisa em design visual, diante de diversas possibilidades de presença, e na participação do designer no seu cotidiano de criar. E, ainda, como as línguas de sinais podem inspirar professores e alunos, no cotidiano de aprender e ensinar o design.

Essa perspectiva investigadora do design e da linguagem é parte da pesquisa desenvolvida pelo grupo imagem(i)matéria ${ }^{1}$ que, por meio de diversas produções textuais e imagéticas, se dedica a estudos que permitam o encontro entre design, arte, linguagem e filosofia. No grupo imagem(i)matéria, assumimos o exercício da teoria no âmbito do projeto e da criação. Vemos no aprofundamento teórico a possibilidade de investigação em projetos que muitas vezes não se aplicam de imediato, entre outros que geram alternativas para novos encontros de saberes diversos. Deixamos aflorar desse exercício teórico o devaneio, o jogo, o encantamento diante do desconhecido, para além de suas intenções de uso, aplicação ao projeto ou às teorias do design.

Como tema de pesquisas desenvolvidas, pensar sobre o gesto ${ }^{2}$ criador a partir da escrita e os movimentos que a derivam, era assunto já familiar ao grupo, pelo estudo de Jacques Derrida, Michel Foucault, Gilles Deleuze e Roland Barthes, entre outros. Nessa interseção entre estudos da linguagem, filosofia e design, no empreendimento de muitos pontos de contato possíveis, nos dedicamos, por exemplo, a pensar sobre a escrita alfabética, sua relação verbal/visual. A ação que se produz nos inúmeros textos, e nas palavras, podendo se expandir em possibilidades de escritura (DERRIDA, 1973), como dinâmica criadora pertencente ao processo do designer e do artista, tanto em suas pesquisas teóricas quanto na elaboração de seus trabalhos, em sua praxis. Isso nos leva a considerar até mesmo, em determinados momentos, uma escrita que resulta como negação da própria letra e da palavra como signo, transfigurando-se em códigos diversos, gesto, movimento em constante transitoriedade de significados.

Desse modo, as indagações provocadas pela possível conexão entre o gesto de escrever e o processo de criação em arte e design se desdobraram há alguns anos em novas perguntas de pesquisa, quando um encontro fortuito ${ }^{3}$ ocorrido em 2016 resultou em uma parceria acadêmica que levou o grupo imagem(i)matéria a retomar uma vertente investigativa, acerca da linguagem, na busca pelo entendimento destas correlações por intermédio do estudo das línguas de sinais. A partir disso, foi possível pensar em alguns elos pré-estabelecidos que vieram a se romper quando imaginamos: o que acontece se o alfabeto e o gesto da escritura, como no caso das línguas de sinais, não representar um som? Ou melhor, se este som representado não se justificar por sua ligação como o 'pensamento' como logos? E se a sua relação com os sentidos possíveis se der de outro modo?

Para além de um novo olhar sobre nossa língua de ouvintes, no Brasil o português, e o uso do alfabeto como escrita, já abordado em pesquisas anteriores do grupo, foi possível realizar nossas primeiras indagações a respeito das ligações possíveis entre o aprendizado das línguas de sinais e o design, mais especificamente o design visual e a comunicação visual.

E, neste momento, desejamos esclarecer pontos mais específicos sobre a oportunidade que estes encontros proporcionam aos designers e estudantes participantes dos projetos, seja por meio do aprendizado da Língua Brasileira de Sinais, como de qualquer outra língua de sinais, ou no entendimento das diferenças culturais que envolvem surdos e ouvintes.

\footnotetext{
${ }^{1}$ Grupo de pesquisa certificado e cadastrado no diretório do CNPq, liderado pelos Professores Doutores Julie A. Pires e Marcelo G. Ribeiro, docentes da Universidade federal do Rio de Janeiro. [imagemimateria.eba.ufrj.br]

2 A palavra gesto, neste artigo, tem a intenção de significar para o leitor qualquer movimento de corpo (voluntário ou involuntário) diferente da concepção da linguística e fonética, na qual "gestos" são considerados "traços paralinguísticos ou extra-linguísticos das línguas orais." (GESSER, 2009: 22)

${ }^{3}$ Nos referimos à parceria estabelecida com as Professoras Doutoras Danielle Mendes e Georgina Martins, do curso de Letras-Libras da UFRJ. Em 2016, a Escola de Belas Artes sofreu um incêndio de grandes proporções em suas instalações, o que nos levou a dividir espaços diversos com a Faculdade de Letras, desde então.
} 
É preciso reconhecer as questões da Cultura Surda para entender melhor seus significados. Convém ressaltar que a Libras é a segunda língua oficial do Brasil, sendo considerada em muitos casos a primeira língua (L1) aprendida por aqueles que são surdos desde o nascimento, ou por aqueles que se tornaram surdos antes de adquirirem a língua falada. E é, portanto, desse modo que a Libras deve ser entendida. O que para as pesquisas em design torna-se instigante, quando buscamos compreender o modo de operar de uma conversa que se dá por meio das mão e do corpo, tendo a visão como um dos principais canais de comunicação.

\section{Surdez e voz}

Embora hoje possamos mapear, por meio das mídias digitais, diversas iniciativas de divulgação de informações sobre a surdez e as línguas de sinais, a surdez foi tratada de diferentes formas nas sociedades humanas.

Na maioria das vezes, a sociedade ouvinte ignorou a opinião dos surdos quanto às decisões a serem tomadas a respeito deles. No Brasil, a educação de surdos começou em 1856 e logo no ano seguinte foi fundado o Instituto Nacional de Educação de Surdos (INES) no Rio de Janeiro, tendo o apoio do Imperador D. Pedro II. No início, o INES foi responsável por currículos que contemplavam a formação dos alunos por educação oral e escrita, enquanto que a "linguagem gestual", como era chamada, permanecia na clandestinidade. Somente na última década século XX, nos anos 1990, depois de uma pesquisa dirigida à discussão do tema, a língua de sinais passou a ser introduzida oficialmente no ensino: "a grande herança dessa experiência foi a presença da língua de sinais pela primeira vez no projeto pedagógico da instituição." (ROCHA, 2008:122)

Anos mais tarde, pela lei $\mathrm{n}^{\circ} 10.436$ de 24 de abril de 2002, a Língua Brasileira de Sinais (Libras) foi reconhecida como "meio legal de comunicação e expressão" constituindo genuíno "sistema linguístico de transmissão de ideias e fatos".

Assim, por se configurar uma língua, a Libras é um sistema simbólico, ou seja, no qual o gesto não necessita guardar semelhança com seu significado. O que nos leva a entender que as línguas de sinais não são mímicas e, assim como as língua verbais, fazem uso de signos arbitrários. Deste modo, os sinais para um mesmo sintagma podem variar até mesmo dentro do próprio País. Há até comunidades fechadas que desenvolvem sua própria língua de sinais e sobre este fato Oliver Sacks nos fala de uma comunidade em que a surdez era algo comum, e por isso todos, incluindo os ouvintes, sabiam a língua de sinais naquele lugar (SACKS, 1998).

No livro "Libras? Que língua é essa? Crenças e preconceitos em torno da língua de sinais e da realidade surda", Audrei Gesser aponta diversas questões que ainda hoje precisam ser esclarecidas para ouvintes que não conhecem as línguas de sinais. A fim de proporcionarmos uma compreensão mais ampla dessas línguas, para melhor leitura das considerações que seguirão neste artigo, convém citar aqui algumas destas reflexões da autora.

O primeiro ponto abordado por Gesser (2011) diz respeito à noção de que a língua de sinais é universal e, embora muitos leitores já possam ser esclarecidos quanto a este dado, preferimos ressaltálo aqui, pois em muitos momentos passados em que realizamos a apresentação dos trabalhos de pesquisa do grupo imagem(i)matéria ou do Trabalho de Conclusão de Curso em Graduação, que descreveremos mais tarde, pessoas da plateia, quase sempre composta por estudantes e professores das áreas de artes e design, desconheciam o fato ou pensavam haver similitudes entre as línguas de sinais espalhadas pelo globo terrestre. Esta ideia, diz Gesser, está "ancorada" na noção de que "toda língua de sinais é um 'código' simplificado aprendido e transmitido aos surdos de forma geral." (GESSER, 2009: 11) O que nos leva a outra confusão, muito comum entre os ouvintes e também apontada pela autora, de que a língua de sinais seria como uma mímica. Uma visão errônea que diz respeito ao próprio modo como a surdez foi encarada ao longo do tempo em nossa sociedade ouvinte, como uma anormalidade. Para Gesser:

...é necessário que nós, indivíduos de uma mesma cultura de língua oral, entendamos que o canal comunicativo diferente (visual-gestual) que o surdo usa para se comunicar não anula a existência de uma língua tão natural, complexa e genuína como é a língua de sinais. (GESSER, 2009: 22) 
A Libras, como todas as outras línguas de sinais, possui gramática própria e é passível de expressar ideias ou conceitos abstratos. Não é, de modo algum, um "código primitivo" ou pantomima, e desta maneira constitui um engano pensá-la como uma língua exclusivamente icônica.

A língua e sinais (...) tem uma gramática própria e se apresenta estruturada em todos os níveis, como as línguas orais: fonológico, morfológico, sintático e semântico. Além disso, podemos encontrar nela outras características: a produtividade/criatividade, a flexibilidade, a descontinuidade e a arbitrariedade. (GESSER, 2009: 27)

Outro fator importante, que deve ser bem entendido pelos ouvintes, é que o uso do alfabeto de sinais (ou datilologia) se destina apenas aos nomes próprios, pessoas ou lugares, siglas, e algum vocábulo que ainda não tenham um sinal correspondente criado. Do contrário, seria como se decidíssemos soletrar cada letra de uma palavra, e frases inteiras letra por letra, durante uma conversa, dificultando, portanto, um diálogo de modo eficaz. Conforme já dissemos, as línguas de sinais são diferentes no mundo todo e, embora algumas possam guardar semelhanças de acordo com a localização geográfica ou fatores históricos, vale notar que até mesmo a configuração do alfabeto manual possui diferenças entre as diferentes línguas de sinais, de distintos locais do mundo (figura1).

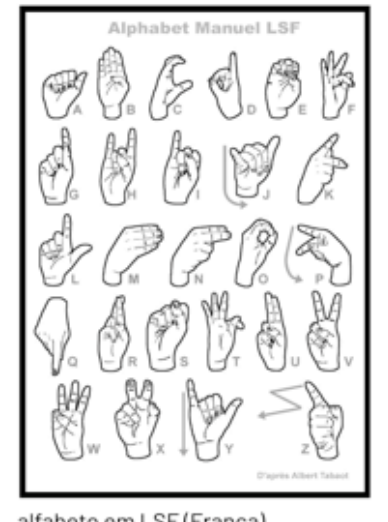

alfabeto em LSF(França)

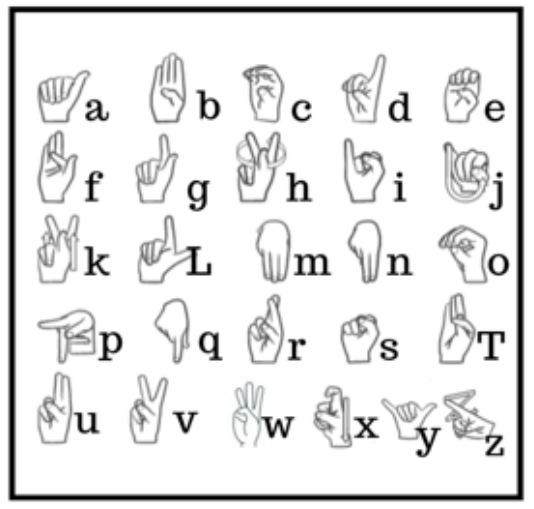

alfabeto em Libras (Brasil)

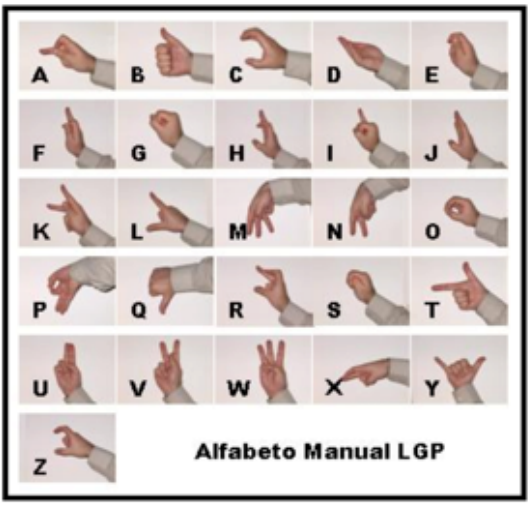

alfabeto em LGP(Portugal)

Figura 1: Alfabetos manuais | Fontes: brasilescola.uol.br e wikipedia.org

Uma curiosidade, relacionada à arbitrariedade presente nas línguas de sinais, é que a Libras se parece mais com a LSF (Langue des Signes Française) do que com a língua oficial de Portugal LGP (Língua de Gestos Portuguesa). Isso se deve ao fato de que os primeiros professores trazidos para o Brasil, no recém criado INES, eram franceses (ROCHA, 2008).

\section{Corpo e conversa}

Ao pensarmos no aprendizado das línguas de sinais, é comum imaginarmos que toda a dificuldade de aprender uma língua de gestos está em memorizar inúmeros sinais e seus significados, sendo que o corpo aprenderia na medida em que houvesse a memorização intencional destes gestos diante da resposta alcançada pela comunicação. Mas a dificuldade da pronúncia, que muitas vezes experimentamos ao aprender uma nova língua falada (nos novos exercícios da boca, na contração da língua nos lábios ou no palato, na ressonância das cordas vocais naqueles vocábulos menos exercitados em nossa língua mãe) é então acrescida pelos movimentos que precisam ser gerados por todo o corpo, mãos, braços, faces, olhos, dorso. Semelhante a um balé, que envolve toda nossa corporeidade, para dar conta da comunicação e expressão que desejamos empreender nesse ato de conversa. O pensamento, do ponto de vista da linguagem, precisa estar conectado ao corpo de modo simultâneo, como na dança, comandando os movimentos para se comunicar, com o olhar atento aos sinais do outro para que o processo possa ter sua continuidade e a compreensão do outro seja 
garantida. Não é possível desviar o olhar e é preciso que o corpo se entenda para se fazer entender também.

Uma enorme dificuldade se estabelece, então, para o estudante de Libras ouvinte, pois alguns gestos são configurações absolutamente novas para esse corpo aprendiz que se comunica noutro sentido, sempre aquém, numa relação de complementaridade à palavra falada. Assim, no aprendizado pela experiência, embora os olhos compreendam o gesto a ser realizado, muitas vezes o corpo não é capaz de reproduzi-los pela falta de familiaridade que tem com tal movimento (mãos, dorso, rosto, braços), necessário para que o sinal se efetive como "palavra".

Além disso, é preciso considerar modelos perceptivos diferentes, pois relembramos Roland Barthes, quando fala sobre a música (BARTHES, 1990), ao afirmar que a audição no ser humano serve como um sensor em todas as direções com o objetivo de nos prevenir do perigo. A visão, por outro lado, seria limitada a uma área do espaço, havendo um foco principal para a atenção o que nos leva à hipótese da falta de audição no surdos acabar acentuando outros sentidos, refletindo em modo diferente de perceber o mundo visualmente (SACKS, 1998). Essas diferenças perceptivas, por exemplo, sugerem pesquisas mais aprofundadas para o desenvolvimento de projetos considerando surdos e ouvintes.

Neste sentido, com enfoque no entendimento da leitura e comunicação possibilitada por imagens, o projeto de extensão "Imagens em Diálogos Possíveis"”, realizado em conjunto com alunos da Escola de Belas Artes e alunos do curso de Letras-Libras, possibilitou trocas estimulantes e impulsionou o aprendizado da Libras, e em alguns casos o aprofundamento de suas questões, para integrantes ouvintes que já falavam Libras ou que se tornaram aprendizes no contato com a língua de sinais.

\section{Escrita e movimento}

Quando abordamos o trabalho com textos e tipografia no design gráfico, é comum, ainda, ouvirmos que a utilização das tipografias racionais, como Helvética, Univers, entre outras, devem prezar pelo argumento da "limpeza visual, "clareza na transmissão do sentido" e eficiência na "legibilidade" de seus caracteres. Há um propósito do design moderno, constituído no exercício profissional e do ensino de design, de que o texto verbal elaborado para mensagem seja "transmitido" sem "ornamentos", numa afirmação do conceito da escrita como representação da voz e da fala.

Nessa lógica representacional do design gráfico moderno, textos são dimensionados para serem lidos como uma representação direta da fala e do pensamento do autor, numa subordinação que privilegia a palavra falada, tendo sua diagramação comprometida com a neutralidade necessária à interpretação imediata deste pensamento pelo leitor. Visão esta que não constitui privilégio do modo de operar do design gráfico moderno, mas que na verdade pode ser justificada pelo que Derrida menciona, em Gramatologia, como uma noção descendente de um logocentrismo ocidental que é também um fonocentrismo, no pensamento linguístico.

A respeito da subordinação da escrita, ainda em Saussure, encontramos um privilégio depositado na fala e a ligação estreita do signo à phoné. (DERRIDA, 1973)

Seria reservado à escrita o papel de significante escrito do significante fonético, este sim originário, diretamente do "pensamento", como logos, na relação com o sentido e a verdade, em uma "significação natural e universal" que seria produzida com a fala. A partir do pensamento de Saussure sobre a dualidade significante/significado. (PIRES, 2020: 98)

\footnotetext{
${ }^{4}$ O projeto de extensão Imagens em diálogos possíveis é Coordenado pelos Professores Julie de Araujo Pires e Marcelo Gonçalves Ribeiro, da Escola de Belas Artes da UFRJ, e conta com a participação da Professora Danielle Mendes, do departamento de Letras-Libras. Tem como objetivo mapear diversas leituras de imagens por meio da integração entre participantes de surdos e ouvintes.
} 
Deste modo, Derrida ${ }^{5}$ desenvolveu importante teoria a respeito da relação escrita/fala, inserindo sua noção de escritura, imprescindível à compreensão dos diversos encontros que o design de comunicação visual pode estabelecer com as línguas de sinais. A primeira convergência, diz respeito à escritura e sua possibilidade de autonomia em se constituir como elemento inaugural. Esse caráter de movimento e provisoriedade da escrita, Barthes também afirma ao mencionar o atributo da escrita que diz respeito ao seu caráter de puro movimento:

Tracem um círculo: produzirão um signo; agora façam-no mover-se: produzirão uma escritura: a escritura é a mão que pesa, avança ou se arrasta, sempre no mesmo sentido, em suma, a mão que trabalha (daí a metáfora rural que designa a escritura bustrofédon pelo movimento de vaivém dos bois que trabalham no campo). (BARTHES, 1990:194)

Ao estar sempre em movimento, a escrita definitivamente se desloca da função de registro da palavra falada, sempre secundário e subordinado, o que nos impulsiona a pensar no design a suas possibilidades a partir dos movimentos corporais de uma língua de sinais, na qual fala dos surdos se dá por uma escrita dinâmica, sempre em movimento, que se constitui no espaço.

Por outro lado, ao pensar na Libras, em sua característica multidimensional, sob a ótica do design visual, encontramos inúmeros desafios em representar seu movimento. Seja por seu caráter dinâmico, muitas vezes de grande complexidade para a apresentação em imagens estáticas, pela sua tridimensionalidade, ou por seus detalhes mínimos, que compõem significativa parte para o entendimento mútuo no diálogo em curso. Devemos considerar, ainda, que a Libras é uma língua essencialmente performática e seu sentido se constrói em dinâmica corporal constante, de quem fala, ao longo de uma conversa. O olhar precisa ser atento e toda informação visual nesse momento importa.

\section{Design como crítica e reflexão}

Pensar no design hoje é abarcar a diversidade. Há uma mudança no pensamento projetual, característica do design neste século, que se inicia da consideração de um estudo particular rumo ao desenvolvimento de um plano geral, sem a imposição de soluções abrangentes ou com foco demasiado em um ser humano idealizado. Também, as certezas de caminhos absolutos, ou a intenção de mudar comportamentos em vista de modelos previstos e controlados pelo "bom design", deram lugar a experimentações diversas, sempre no sentido de transformar o ato projetual no que tange o design projetado "para" o ser humano, no espaço de criação do design "com" o ser humano.

Assim, a metodologia projetual, estudo comum ao design de comunicação visual, e hoje também presente nas investigações em artes visuais, sofreu transformações significativas em sua formulação, uma vez que aquela metodologia “... até então aplicada (...) traz na sua essência as referências do cenário estático presente no modelo moderno, em que normalmente os elementos eram de fácil decodificação, por não serem híbridos, e quase sempre de conteúdos previsíveis por ainda não ter havido o mix de informações fortemente presente no processo de globalização." (DE MORAES, 2010:17)

Os mesmos meios e tecnologias que tornaram acessíveis esta multiplicidade de informações, em conteúdos textuais e imagéticos, devem ser encarados no âmbito do design visual como fonte e recurso para pesquisas que envolvam o conhecimento e a divulgação de novos projetos, responsáveis pela inserção social do maior número de indivíduos possível.

\footnotetext{
5 Derrida afirma que:“(...) dentro deste logos, nunca foi rompido o liame originário e essencial com a phoné. Seria fácil mostrá-lo e tentaremos precisá-lo mais adiante. Tal como foi mais ou menos implicitamente determinada, a essência da phoné estaria imediatamente próxima daquilo que, no 'pensamento' como logos, tem relação com o 'sentido'; daquilo que o produz, que o recebe, que o diz, que o 'reúne'. (...) Entre o ser e a alma, as coisas e as afecções (affection), haveria uma relação de tradução ou de significação natural; entre alma e logos, uma relação de simbolização convencional. (...) E a primeira convenção, a que se referiria imediatamente à ordem da significação natural e universal, produzir-se-ia como linguagem falada." (DERRIDA, 1973:13).
} 
Além disso, a propósito de pesquisas, no campo do design, de autores como Ellen Lupton e Abbott Miller (2011), e reflexões teóricas como a de Bruno Latour (2009), abre-se ainda a possibilidade do processo projetual, em design, constituir uma ferramenta crítica e um meio de pensar as relações entre os seres humanos e operar profundas transformações nas diversas interações sociais.

O autor Oliver Sacks, no prefácio de seu livro "Vendo Vozes", nos descreve a língua de sinais como "Uma língua completamente visual". (SACKS, 1998) Em meio ao grande números de línguas de sinais espalhadas no mundo, a Língua Brasileira de Sinais (Libras), em seu aspecto visual, constitui o principal modo de comunicação, conhecimento e expressão para o surdo no Brasil, principalmente para aqueles que aprenderam os sinais como a primeira língua, constituindo o cerne de sua interação com o mundo, comunicação que neste caso ocorrerá entre surdos e ouvintes que aprenderam a Libras, ou em alguns casos por meio de intérpretes.

Mas, apesar do pouco conhecimento que a maioria dos ouvintes tem sobre as línguas de sinais, o que Sacks nos apresenta, em seu livro, permite um vislumbre, por meio de histórias de extraordinários desafios linguísticos, do que enfrentam aqueles que aprenderam a se comunicar, primeiramente, pelo sistema de sinais, totalmente diferente em diversos aspectos da língua materna falada pelos ouvintes.

Nesse contexto, diversos projetos no campo do design, dedicados à surdez e à inclusão social, envolvem pesquisas no Brasil sobre o ensino em Libras, a criação de conteúdo digital para surdos, desenvolvimento de tecnologias assistivas, e realização de projetos para educação inclusiva e bilíngue, entre outros. Essas iniciativas buscam refletir sobre as diferenças sociais existentes e devem, cada vez mais, inserir no espaço de criação projetual a participação de surdos, como tentativa de estabelecer enfoques de pesquisa e desenvolvimento de artefatos distintos, materiais e digitais, que aproximem surdos e ouvintes, considerando a complexidade do tema e as disparidades existentes nestas duas formas de expressão e comunicação.

No âmbito do grupo imagem(i)matéria, algumas investigações na fronteira design-arte exploram o estranhamento de um espaço de comunicação, aberto pela experiência do aprendizado da Língua Brasileira de Sinais (Libras), como ponto de partida, para refletir sobre a arbitrariedade linguística da palavra falada e as relações entre sonoridades e significações: gesto, escrita e sentido.

$\mathrm{O}$ uso da língua de sinais, quando estudado pela Neurociência abre perspectivas que consideram o sistema nervoso "livre para assumir formas completamente diferentes, respeitando as limitações das possibilidades genéticas." (SACKS, 1998:56). Por outro lado, no âmbito da linguística, o estudo da gestualidade e da escrita, relacionados a "uma simbolicidade pré-verbal", para Julia Kristeva "parece constituir (...) uma zona rebelde ao ensino cartesiano da equivalência entre o sujeito e o seu verbo, e introduzir assim na razão verbal um elemento subversivo, o pré-sentido..." (KRISTEVA, 1969:350). Nesta dupla ruptura, que a investigação da comunicação pelo uso de sinais permite, emergem inúmeras problemáticas para o design e as artes, em seu caráter visual e multimidiático.

Entre os diversos artefatos criados nas pesquisas do grupo imagem(i)matéria, há trabalhos de grandes formatos, com utilização de realidade aumentada, pequenos objeto e vídeos como a montagem da obra "gesto-silêncio: diálogo multidimensional sem palavras", apresentado em 2017, na cidade do Porto, Portugal. Este trabalho de edição em vídeo inclui imagem em movimento (interpretação do sinal de "mar" em Libras), fotografia (imagens de mar) e áudios (sons do trânsito de uma rua movimentada do Rio de Janeiro capturados em várias manhãs ao longo de uma semana) e sua exposição foi realizada em monitor de TV. O vídeo, com suas imagens e sonoridades, permite ao espectador experimentar diversas relações, não lineares e descentralizadas, para a comunicação em coordenadas espaço-temporais diversas. Ligações que podem ir desde associações que exploram a arbitrariedade do signo linguístico, na relação entre uma imagem acústica e seu significado, à possibilidade de proporcionar novas conexões entre som, gesto e sentido, no diálogo sem palavras de uma língua performática e multidimensional, a Libras.

\footnotetext{
${ }^{6}$ Inspirado nas obras de René Magritte, Christine Sum Kim e Paulo Vivacqua.
} 


\section{Design: prática e reflexão}

Vivemos hoje, mais que nunca, inúmeras relações do cotidiano intermediadas por telas. Interfaces de aparelhos eletrônicos diversos que ocultam sistemas complexos de modo a garantir seu uso e sua operação pelos humanos, sem que a maioria deles tenha alguma ideia do seu funcionamento ou a capacidade necessária para reproduzi-los. Nossos dedos teclam, se movimentam e deslizam sobre as superfícies diversas, de smartphones a tablets e monitores, entre outros, ignorando a enorme rede de informações necessárias para que cada comando se realize e cada tarefa seja cumprida com o desempenho por nós desejado. Contudo, não são raras as vezes que voltamos nosso interesse ao uso de aparelhos mecânicos-analógicos, que se movem pela força dos gestos, mostram seu interior com clareza, e apresentam de forma compreensível suas possibilidades em se multiplicar.

Nesse contexto analógico do design, como exemplo de artefatos desenvolvido com finalidade específica para o aprendizado da Libras, citamos aqui o projeto "Brinquedos Óticos para o Ensino de Libras", realizado pelo estudante Moisés Colares Barreto, integrante do grupo de pesquisa imagem(i)matéria. Projeto em design visual, orientado pela professora Julie de Araujo Pires e coorientado pelo professor Marcelo Gonçalves Ribeiro, que teve sua origem em bolsa do Programa de Iniciação à Pesquisa Artística e Cultural (PIBIAC-UFRJ) e, mais tarde, foi aperfeiçoado como Trabalho de Conclusão de Curso em Comunicação Visual Design.

É importante ressaltar que, embora haja variado conhecimento e experiência dos orientadores com metodologias de ensino e pesquisa, e ainda considerando a larga atuação profissional de mais de 20 anos de em projetos de caráter editorial, no âmbito do design, optou-se por não enquadrar o desenvolvimento deste projeto em metodologia específica. Ainda que possam ser identificadas em algumas etapas do projeto ações surgidas de metodologias diversas, como a observação participante ou a prática reflexiva (HASEMAN, 2015; FINDELI, 2001). E, em se tratando da área de atuação, também nos desviamos dos rótulos de design social ou design centrado no humano por considerarmos que os rumos tomados foram se configurando por meio dos contatos estabelecidos nas práticas efetivas, nos encontros ocorridos, sem que houvessem parâmetros previamente estabelecidos no projeto.

Ao considerar a Libras como palavra em movimento, e devido a facilidade de registro e conexão por vídeo permitida pelo uso de celulares e tablets, percebemos que se inicia, atualmente, de modo mais significativo, o processo de registro da Cultura Surda e uma comunicação mais abrangente entre os membros dessa comunidade. O que nos leva a imaginar e refletir sobre o quanto era difícil a interação desses grupos antes dos avanços atuais da informática. Por outro lado, quando elaboramos projetos, no âmbito do design, considerando utilizar esses recursos como meio inclusivo no ensino, percebemos que se faz necessária a presença de aparelhos eletrônicos em bom funcionamento e com softwares atualizados. O que nem sempre encontramos disponível em escolas, nas salas de aula, principalmente para os estudantes da rede pública de ensino, por representam ainda um custo relativamente alto. Desse modo, a solução mais rentável para o ensino de Libras nessas instituições continua sendo o uso de materiais didáticos impressos, sejam estes feitos de forma amadora como cartazes, desenhos, painéis e até esculturas, ou formalmente através de livros didáticos. Se observarmos os livros e a maioria dos materiais disponíveis para o ensino de Libras, podemos notar muitos desafios a serem encarados nos encontros possíveis entre a surdez e o design visual.

Dentro de uma sala com crianças surdas, muitas delas aprendendo pela primeira vez um idioma, pude chegar à ideia de trabalhar com o movimento em um suporte estático, utilizando o espaço da sala de aula para criar um sala de brinquedos óticos, em que a magia do movimento acontece através do movimentar das mãos para ativar os brinquedos, e onde se é respondido também pelas mãos animadas. (BARRETO, 2019: 7)

A partir desse convívio, entre um estudante de design e crianças aprendizes da Libras, o projeto foi ganhando forma e se justificando pela possibilidade de ser elaborado a partir do uso de materiais de fácil acesso ao ambiente escolar, como papel, papelão, estiletes, grampos, impressoras domésticas e softwares de código aberto. A ideia de utilizar os brinquedos ópticos, experimentos sobre a percepção visual e a criação e registro de imagens, datados desde a primeira metade do século XIX, se deu pelo fato de que uma simples observação sobre estes artefatos basta para sermos capazes de compreender todo seu 
funcionamento. Abordagem cognitiva diferente do que acontece com uma filmagem ou reprodução de um vídeo digital, em que não é possível ver o que acontece no interior do dispositivo eletrônico.

Por outro lado, as línguas de sinais fazem uso do gesto como meio de expressão, têm a visão como principal sentido para a comunicação, e em grande parte os sinais são feitos com as mãos, embora possam ter seu significado alterado ou enfatizado através da expressão do rosto e da posição das mãos em relação ao corpo. Em toda conversa estabelecida por meio das línguas de sinais, as mãos são indispensáveis e percebemos, a partir de um levantamento preliminar do projeto, que muitas ilustrações representativas dos sinais de Libras, já existentes, as mãos das personagens eram pequenas demais ou a suas faces pouco expressivas na composição. Em muitos dos desenhos, naqueles sinais que necessitavam da visualização do movimento para serem compreendidos, a representação se tornou ainda mais complicada em alguns casos, pois foi necessário mostrar configurações diferentes para cada um dos momentos distintos do movimento, o que nas reproduções de imagens estáticas acabou sendo solucionado por meio de setas e sobreposições, tornando a leitura final passível de desentendimento.

$\mathrm{O}$ recurso dos brinquedos óticos, adotado no projeto, surgiu então na intenção de resolver justamente esse impasse, entre o movimento e a representação bidimensional estática. O flipbook (ou folioscópio), datado de 1868, foi o primeiro brinquedo a ser utilizado em uma experimentação inicial do projeto. Sua criação e funcionamento, entre os outros recursos selecionados, é a mais fácil de ser desenvolvida e realizada (dentre os brinquedos óticos que necessitam mais de dois frames para provocar a ilusão do movimento) com o número de etapas necessárias à maioria dos sinais. A elaboração de um flipbook é de relativa simplicidade e durante o momento de checagem do movimento, basta folhearmos as páginas pelas bordas do papel, com as mãos, para ver a animação acontecer.

Nesse projeto, como um dos primeiros testes realizados, foram manufaturados pequenos blocos de papel em gramatura $90 \mathrm{~g} / \mathrm{m}^{2}$, lembrando o formato de post-its, que mostravam os sinais relacionados a cada um dos dias da semana, sinais para os nomes dos meses e representações dos numerais para designar o ano em Libras, formando um calendário animado, facilmente reproduzível e montado com materiais simples nos ambientes escolares (figura 2).

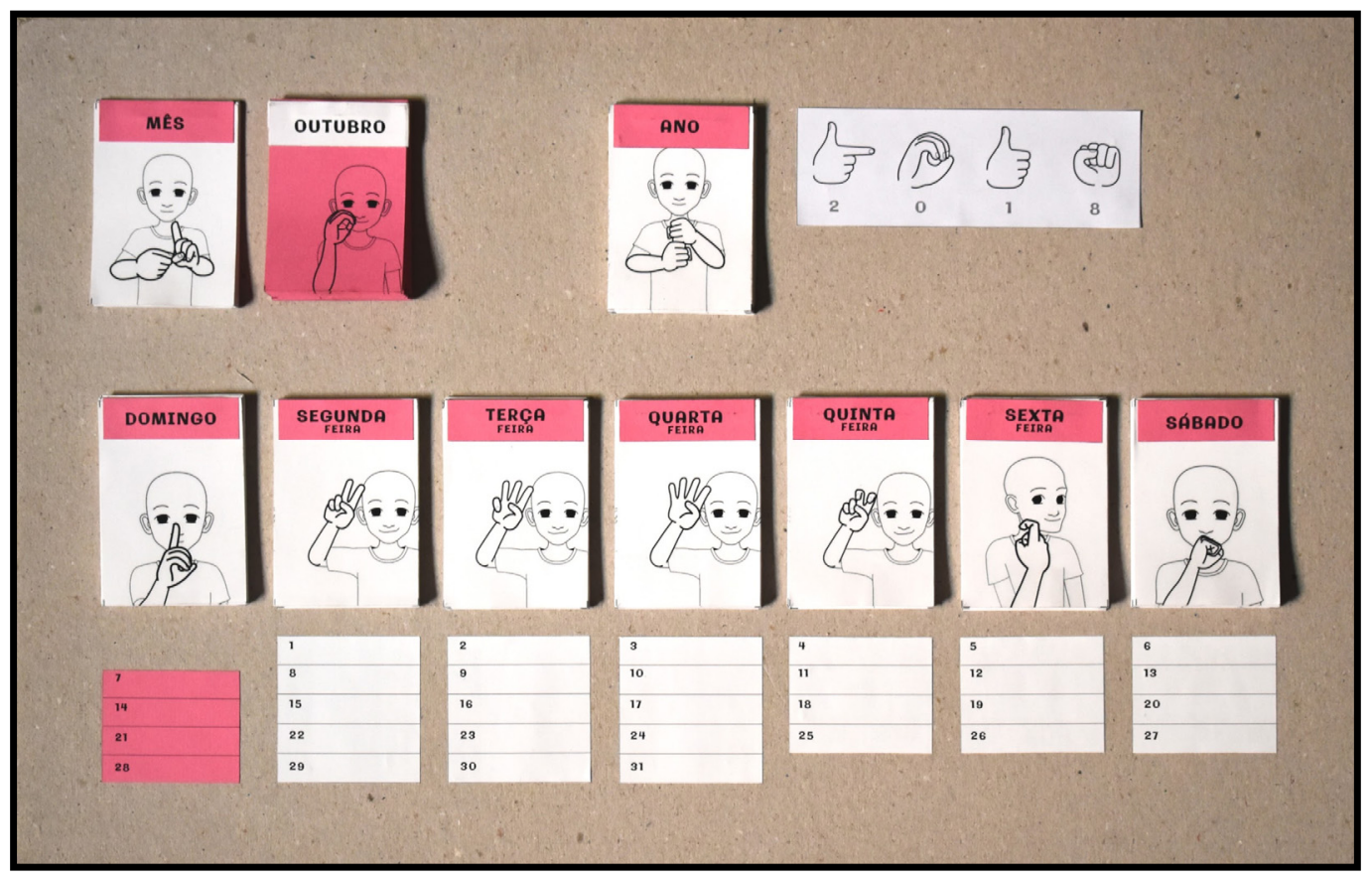

Figura 2: Calendário em Libras | Fonte: autor

Nesse primeiro estágio da pesquisa, as animações foram desenvolvidas em desenhos quadro a quadro feitos à mão. Como parte de todo processo, a realização das três primeiras animações à mão foi um exercício muito enriquecedor para a compreensão mais detalhada do funcionamento da animação tradicional em suas raízes, possibilitando um domínio maior do processo que vai desde o planejamento dos frames até a visualização do movimento acontecendo ao "flipar" as páginas. Entretanto, a 
quantidade de movimentos planejados, a partir dos sinais selecionados para animar, e o investimento em tempo necessário para viabilizar todo o projeto, impulsionou a decisão pelo uso de softwares livres, para o desenvolvimento das etapas seguintes do trabalho.

No que diz respeito aos detalhes da representação, durante o processo de projeto, outras questões foram surgindo como por exemplo a aparência da personagem, que se objetivou ser o mais legível possível, a expressão da emoção facial, e a tentativa de trazer uma personagem que fosse de possível identificação com o maior número de crianças, sem valorizar algum gênero ou cor.

Em relação ao esquema de traçado e finalização do desenho foi escolhida a representação pelo contorno das formas, sem preenchimento, com o intuito de diminuir o custo de impressão, com economia de tinta, pois um dos objetivos do projeto desde seu início foi de que tivesse o menor custo possível de modo a permitir sua reprodução nas escolas.

Quanto aos outros critérios na definição da personagem, foram tomados como base os chamados Parâmetros da Libras (MONTEIRO, 2008), que dizem respeito à estrutura gramatical da língua:

- CM - Configuração de Mãos (combinação das posições dos dedos)

- L - Localização ou ponto de articulação (espaço em frente ao corpo ou uma região do próprio corpo, onde os sinais são articulados como: tronco, rosto, testa, acima da cabeça, etc.)

- $\mathrm{M}$ - Movimento (havendo movimento no sinal, qual sua trajetória)

- Or - Orientação da mão (sentido em que a palma da mão está virada)

- ENM - Expressões Não-Manuais (como as expressões faciais)

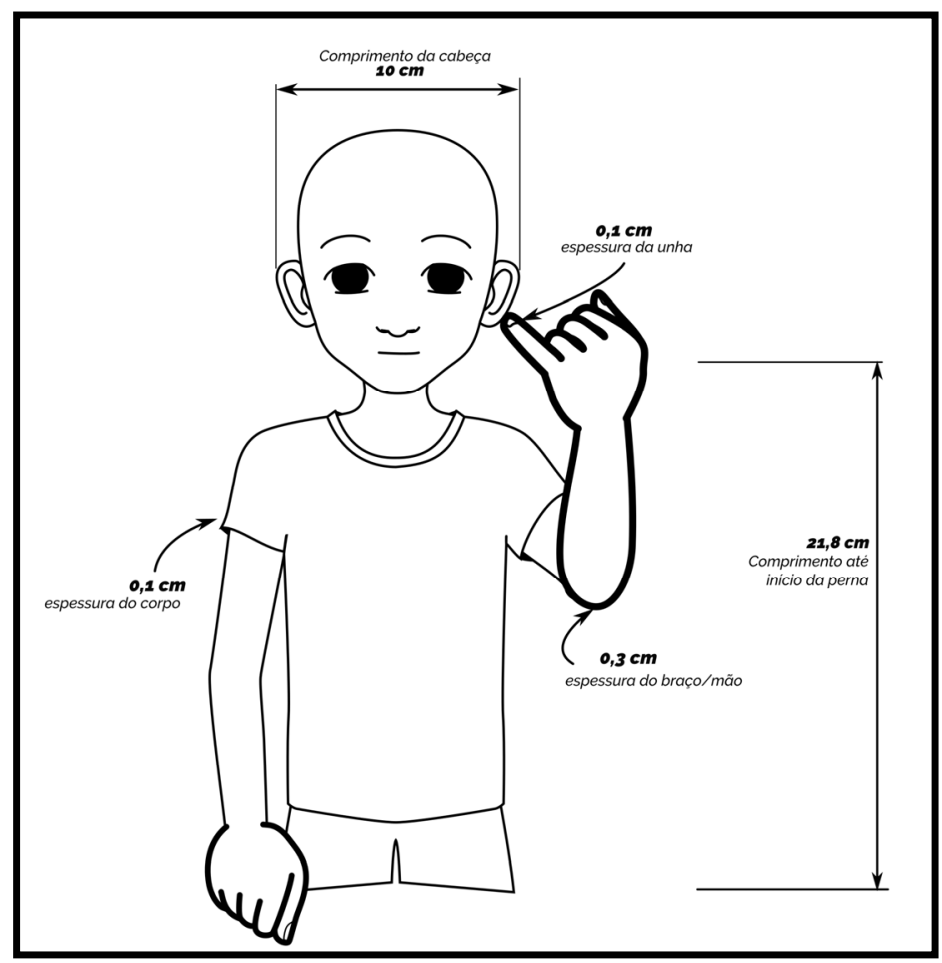

Figura 3: diferenças de traçados no desenho com base na estrutura gramatical da Libras | Fonte: autor

Foi também uma decisão do projeto, que a ênfase maior, na configuração da personagem, seria dada às mãos, realizada com um contorno mais grosso, se destacando do restante do desenho. $\mathrm{O}$ desenho da cabeça estaria em segundo plano na hierarquia visual, para destacar a expressão da personagem, e, por último, apareceria o tronco, em proporção menor de modo a configurar um plano de fundo (figura 3 ).

Assim, CM e Or puderam ser destacados pela espessura maior do contorno da mão e do antebraço, deixando-os em primeiro lugar na hierarquia visual. Quanto ao ENM, ao aumentar a proporção da cabeça da personagem, e também a proporção dos olhos em relação à cabeça, foi possível usá-los como principal meio expressivo da face. A Localização (L) por sua vez definiu o 
enquadramento da personagem, de forma que o rosto e a trajetória do movimento ficassem sempre aparentes na animação, pois na Libras a maioria dos sinais são feitos da cintura para cima. E, por fim, o parâmetro Movimento (M), que confirmou a razão pela qual as técnicas de animação foram utilizadas neste projeto.

Quanto à configuração dos artefatos, um dos principais objetivos desse trabalho era tornar os brinquedos óticos facilmente reproduzíveis, em todas as suas etapas, sendo possível realizar seu processo e sua reprodução por meio de um computador simples, impressora e materiais de corte e colagem. Isso inclui também o uso de softwares de licença aberta, que podem ser baixados pelo usuário final, educadores, pais e estudantes, de modo a modificar os modelos e criar novos sinais e suas aplicações.

Outra questão importante, quanto a adequação dos brinquedos aos sinais da Libras, foi observada a partir da repetição de movimento presente em alguns sinais. Fato que expandiu a pesquisa ao desenvolvimento de outros dois artefatos, desta vez na animação de movimentos em ciclo.

O Fenaquistoscópio (fenacistoscópio) e o Zootrópio são brinquedos que se diferenciam do flipbook por sua animação ser cíclica, necessitando assim de um número de frames menor, em função da repetição dos movimentos. O primeiro é um brinquedo em forma de disco, com fendas radiais, abertas no mesmo número de frames desenhados no disco. A percepção do movimento ocorre quando, ao girar o disco diante de um espelho, visualizamos o movimento acontecer pelas fendas abertas.

Já o Zootrópio é um objeto em forma cilíndrica, com fendas na parte lateral, também na mesma quantidade dos frames, que quando girado, em torno de um eixo fixado no centro da base, é possível lançar o olhar de fora, pelas fendas, e ver a animação acontecer dentro o cilindro. A maior dificuldade em reproduzir esse brinquedo diz respeito à precisão necessária para que sua rotação aconteça exatamente no eixo perpendicular que atravessa o centro da base, pois do contrário ele perderá sua estabilidade, comprometendo a observação do movimento.

Ao longo de todo desenvolvimento desse projeto, algumas perguntas ocuparam nossos debates, entre orientando e orientadores, em apresentações do trabalho no ambiente acadêmico, nas escolas para surdos ou para profissionais que atuam no ensino inclusivo, sempre no sentido de confirmar sua viabilidade, o interesse em seu desenvolvimento e as particularidades desses artefatos diante de toda a tecnologia digital oferecida no mundo de hoje.

Guiados pela pergunta inevitável: "qual seria, assim, a vantagem de se trazer essa nova proposta para o ensino da Libras?", percebemos hoje que, após algumas contribuições as quais somos gratos e que possibilitaram os avanços da pesquisa, podemos enumerar algumas características que se destacam nesse tipo de mídia em relação às mídias digitais:

1. Os brinquedos óticos permitem observar o movimento do gesto no ensino da Libras, ainda que usando um suporte estático, que é a folha de papel.

2. Por não necessitar de um aparato eletrônico no ato de sua reprodução para os alunos, de modo que todo o processo pode ser feito apenas com um computador, impressora e algumas ferramentas encontrados em papelarias, os brinquedos são produzidos com baixo custo e materiais presentes em qualquer escola.

3. Conforme dito acima, diferente do que ocorre num vídeo, desde a câmera até a tela de reprodução, a animação com brinquedos óticos é um processo aberto à observação de seu funcionamento, a "olho nu", pelo qual o usuário pode compreendê-lo e, se desejar, reproduzílo em todas as suas etapas de confecção.

4. Enquanto nas apostilas, ou na tela de algum dispositivo, é empreendida uma postura com certa passividade diante do conteúdo, no aprendizado com os brinquedos óticos o aluno participa ativamente do seu funcionamento. Ele precisa interagir diretamente com o objeto, controlando o tempo do movimento, interrompendo o processo, observando quadro a quadro do sinal (neste caso também o vídeo normalmente é ineficiente, pois o movimento aparece borrado, dificultando a observação de alguns instantes do sinal realizado).

5. E, por último, consideramos seu uso importante por divulgar junto à comunidade surda a técnica da animação, de forma clara e aberta, para que possa ser utilizada e enriquecer ainda mais sua cultura, incentivando surdos a produzirem suas animações, sob seu próprio olhar. 


\section{Considerações finais}

O design, como atividade projetual, de ensino e pesquisa, sempre se caracterizou por suas trocas com outras áreas de estudo, confirmando sua condição interdisciplinar e transdisciplinar. As reflexões e os exemplos aqui apresentados, mais do que reforçar esse caráter transversal da profissão, e das investigações em design, procura ressaltar a riqueza existente quando nos permitimos estabelecer relações com diversos saberes e, principalmente, no reconhecimentos de realidades culturais e linguísticas diversas. Ao experimentarmos o aprendizado da Libras, e nos deixarmos envolver pelas oportunidades perceptivas trazidas por uma Cultura Surda, que utiliza uma língua com canal comunicativo (visual-gestual) diferente daquele adotado por nós, ouvintes, podemos encontrar caminhos para a pesquisa e a prática do design que vão muito além de uma solução projetual para um problema específico. Notamos, também, que as fronteiras se tornam mais fluidas entre as questões de nossa comunicação oralizada, em seu imbricamento com a profusão de imagens do cotidiano contemporâneo, principalmente no que diz respeito ao nosso entendimento dessas imagens, e à atenção necessária aos processos de mediação que estabelecemos diariamente em todas as áreas de nossa vida.

Refletir sobre a arbitrariedade de uma língua, oral ou gestual, pensar sobre a investigação em design como uma possibilidade de problematizar barreiras linguísticas e sociais, deixar que um "problema" de projeto possa se transformar em oportunidade para que o designer transforme seu processo criador em um acontecimento onírico, são alguns dos objetivos que almejamos até aqui. Vemos nessa postura um caminho para novos modos de atuação investigativa no ensino e na pesquisa, para além de rótulos ou classificações do design. Como, por exemplo, as possibilidades abertas pela presença marcante do gesto, das mãos e do envolvimento corpóreo, trazido pelas línguas de sinais, expressada pelo desejo em compreender sob a ótica da pesquisa em design, de que maneira o designer se afastou de tempos em tempos, em sua prática profissional, de suas habilidades materiais e do seu próprio corpo. Talvez as exigências operacionais das tecnologias utilizadas, ou as transformações processuais no design, diante das novas mídias e das demandas digitais instauraram outros modos de entendimento dos seus gestos e do seu fazer, cada vez mais, deslocando-o de sua experiência corpórea, e das mãos, para uma experiência do intelecto e do olho. Quando, para nós, não é possível separar essas coisas. Há um empobrecimento representado pelo adormecimento do corpo na ação projetual, assim como na desvalorização do uso dos sentidos em detrimento de uma primazia dos estímulos oculares, de uma noção de percepção limitada (centrada no olho). É preciso retomar, no design, abordagens como a de Richard Sennett, em "O Artífice" (2015). E, ainda, rever a atuação das mãos e do gesto diante da matéria, no exercício criador e de reconhecimento do mundo.

Por fim, deixamos aqui nossos sinceros agradecimentos aos professores, estudantes e intérpretes, do Instituto Nacional de Educação de Surdos (INES), do CIEP José Pedro Varela (Rio de Janeiro), e da Faculdade de Letras (Setor Letras-Libras) da UFRJ, que compartilharam de forma generosa seus conhecimentos sobre Surdez e Libras, em inúmeros debates nas diversas etapas das ações de pesquisa e extensão que permitiram o desenvolvimento e a escrita e deste trabalho.

\section{A sign language power: gesture lessons for design now}

Abstract: This work reflects on the exchanges between design and Brazilian Sign Language (Libras) and Deaf culture. These arose through teaching, research, and university extension activities. The relationship between design investigations and sign languages are configured here as a two-way street. It can bring both possibilities when design can guarantee a voice and social inclusion for all human beings, and it can emerge questions in contact with a language that uses the visual-gestural communicative channel. As examples of these approaches, we present projects developed by the authors of this article, considering creative boundaries between design-art and design to objects of learning Libras. These project situations have an experimental character and an investigative stance, to broaden horizons about the image understanding, language, sign languages, and our language, the Brazilian spoken Portuguese. 


\section{Referências bibliográficas}

BARRETO, Moisés Colares. Brinquedos óticos para o ensino de libras. 2019. $38 \mathrm{f}$. Trabalho de Conclusão de Curso (Graduação em Comunicação Visual - Design). Orientação Julie A. Pires e Marcelo G. Ribeiro. Escola de Belas Artes, Universidade Federal do Rio de Janeiro, Rio de Janeiro, 2019.

BARTHES, Roland. O óbvio e o obtuso, Nova Fronteira. Rio de Janeiro: 1990.

CRUZ, Gabriel Filipe Santiago. Brinquedos Óticos Animados e o Ensino de Design. Rio de Janeiro, 2017. Tese (Doutorado em Design), Pontifícia Universidade Católica 2017.

DE MORAES, Dijon. Metaprojeto: o design do design. São Paulo: Blücher, 2010.

DERRIDA, Jacques. Gramatologia. São Paulo: Perspectiva/ Ed. Da Universidade de São Paulo, 1973.

FINDELI, Alain. Rethinking Design Education for the 21st Century: Theoretical, Methodological and Ethical Discussion. In: Design issues, volume 17, number 1, winter, 2001. Pp.5-17.

GESSER, Audrei. Libras? Que língua é essa?: crenças e preconceitos em torno da língua de sinais e da realidade surda. 1 ed. São Paulo: Parábola Editorial, 2009.

HASEMAN, Brad. Manifesto pela Pesquisa Performativa. Resumos do Seminário de Pesquisas em Andamento PPGAC/USP, São Paulo, 2015.

KRISTEVA, Julia. História da Linguagem. Lisboa: Edições 70, 1969.

LATOUR, Bruno. "A Cautious Prometheus? A Few Steps Toward a Philosophy of Design (With Special Attention to Peter Sloterdijk)". In: Hackne, F.; Glynne, J.; Minto, V. (eds.). Proceedings of the 2008 Annual International Conference of the Design History Society. Falmouth, 3-6 September 2009, e-books, Universal Publishers, pp. 2-10.

LUPTON, Ellen; MILLER, J. Abbott. Design Escrita Pesquisa. Porto Alegre: Bookman, 2011.

MONTEIRO, M. S. História dos movimentos dos surdos e o reconhecimento da Libras no Brasil. ETD Educação Temática Digital, v. 7, n. 2, p. 292-305, 13 nov. 2008.

PIRES, Julie A. Design...Arte: entre as fronteiras da palavra e do gesto. In: GRIMALDI, Madalena / PIRES, Julie (org.) Arquivos 30: especial do Programa de Pós-Graduação em Design. 1a ed. - Rio de Janeiro: Rio Book's, 2020.

ROCHA, Solange. INES e a educação de surdos no Brasil: aspectos da trajetória do Instituto Nacional de Educação de Surdos em seu percurso de 150 anos. Rio de Janeiro: INES, 2008.

SACKS, Oliver. Vendo vozes: uma viagem ao mundo dos surdos. Tradução Laura Teixeira Motta, São Paulo: Companhia das Letras, 1998.

SENNETT, Richard. O Artífice. Tradução: Clovis Marques. 5a ed. Rio de Janeiro: Record, 2015.

TV INES. Aula de Libras - meses e estações. TV INES: 25 de agosto de 2014. Disponível em http://tvines.org.br/?p=4721. Acessado em 12/08/2019, às 07h33min.

WILLIANS, Richard. The Animators Survaival Kit: A manual for Methods, principles and formulas for classical, computer, games, stop motion and internet animators. Estados Unidos: Faber \& Faber, 2012. 